\title{
Pulmoner Arteriyovenöz Malformasyonda Klasik Triad: Çomak Parmak, Siyanoz ve Polisitemi
}

\author{
Classical Triad in Pulmonary Arteriovenous Malformation: Clubbing, \\ Cyanosis and Policytemia
}

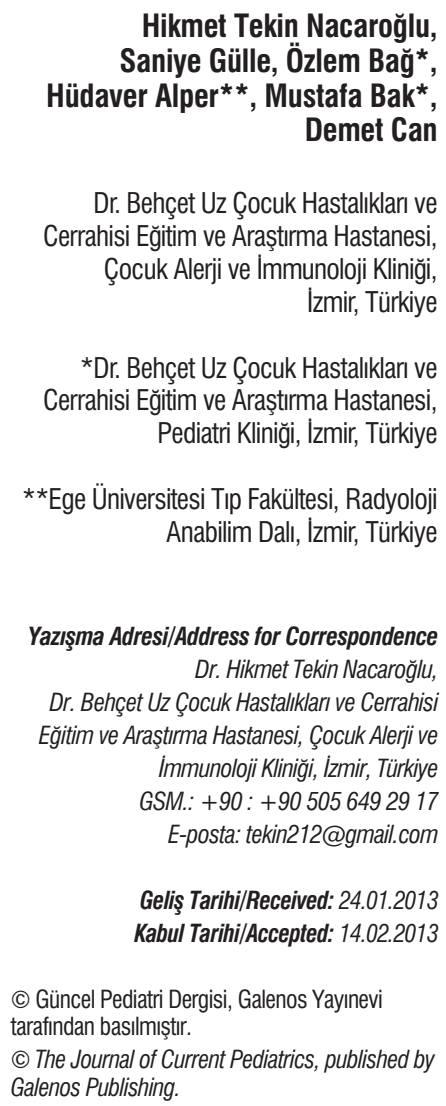

Hikmet Tekin Nacaroğlu, Saniye Gülle, Özlem Bağ *, Hüdaver Alper**, Mustafa Bak*, Demet Can

Dr. Behçet Uz Çocuk Hastalıkları ve Cerrahisi Eğitim ve Araştırma Hastanesi, Çocuk Alerji ve Immunoloji Kliniği, Izmir, Türkiye

*Dr. Behçet Uz Çocuk Hastalıkları ve Cerrahisi Eğitim ve Araștırma Hastanesi, Pediatri Kliniği, lzmir, Türkiye

**Ege Üniversitesi Tıp Fakültesi, Radyoloji Anabilim Dall, lzmir, Türkiye

Yazışma Adresi/Address for Correspondence Dr. Hikmet Tekin Nacaroğlu, Dr. Behçet Uz Cocuk Hastalıkları ve Cerrahisi Eğitim ve Araştırma Hastanesi, Çocuk Alerï ve İmmunoloji Kliniği, lzmir, Türkiye GSM.: +90 : +90505649 2917 E-posta: tekin212@gmail.com

Geliş Tarihi/Received: 24.01.2013 Kabul Tarihi/Accepted: 14.02.2013

(c) Güncel Pediatri Dergisi, Galenos Yayınevi tarafindan basilmıştrir.

(C) The Journal of Current Pediatrics, published by Galenos Publishing.

\section{ÖZET}

Pulmoner arteriyovenöz malformasyonlar (PAVM) anormal kapiller gelişimden kaynaklanan, genellikle konjenital lezyonlardır. Lezyonlar izole tek bir anomali şeklinde görülebileceği gibi otozomal dominant geçişli herediter hemorajik telenjiektazi (Rendu-Osler-Weber sendromu; ROWS) ile birlikte çok sayıda da olabilir. Bu vakalar asemptomatik olabilecekleri gibi efor dispnesi, çarpıntı ve çabuk yorulma da görülebilir. Klasik radyolojik görünümü yuvarlak, düzgün sınırlı lezyonlardır. Bilgisayarlı toraks tomografisi ve anjiyografi de teşhis için faydalıdır.Burada çomaklaşma ve siyanoz ile PAVM tanısı alan 2 ve 13 yaşlarında iki kız olgu sunulmuştur. (Güncel Pediatri 2013; 11: 92-5)

Anahtar kelimeler: Arteriyovenöz malformasyon, çomak parmak, siyanoz

\section{SUMMARY}

Pulmonary arteriovenous malformations (PAVM) are generally congenital lesions that results from an abnormal capillary development. Lesions can be presented as an isolated single anomaly, or may be multiple when accompanying with autosomal dominant hereditary hemorrhagic telangiectasia (Rendu-Osler-Weber Syndrome; ROWS). These cases may be asymptomatic, but exertional dyspnea, palpitations and easy fatigability may also be seen. The classic radiological appearance is a round, well-circumscribed lesions. Computed tomography of thorax and angiography are also useful for diagnosis. Herein, we present 2 and 13 years old girls with the diagnosis of PAVM with clubbing and cyanosis. (Journal of Current Pediatrics 2013; 11: 92-5)

Key words: Arteriovenous malformation, clubbed fingers, cyanosis

\section{Giriş}

Pulmoner arteriyovenöz malformasyonlar (PAVM), venöz ve arter pleksusları arasındaki primitif bağlantıları bölen vasküler septanın inkomplet olușumu veya disintegrasyonundan kaynaklanır. Bu nedenle pulmoner arteryal kan, kapiller yatağa girmeden pulmoner venöz sisteme gecer. PAVM'lerin \%70'den fazlası konjenitaldir (1-3). Konjenital AVM'lerin de \%47-80'i Rendu-OslerWeber hastalığı (ROWH) ya da herediter hemorajik telenjiektazi (HHT) olarak bilinen otozomal dominant geçişli patoloji ile birlikte bulunur (4). Ayrıca HHT ile birlikte olan PAVM'ler diffüz olup hızlı progresyon gösterirler bu nedenle komplikasyon oranları oldukça yüksektir (3). PAVM'li hastalarda görülen semptomlar nefes darlığı, çarpıntı, egzersiz intoleransı, epistaksis, öksürük ve hemoptizidir. Ayrıca sağdan sola şantı \%30 ve daha fazla olan hastalarda siyanoz, polisitemi ve çomak parmaktan oluşan klasik triad görülür. Kalsik triadın görülme sıklığı \%20 civarındadır $(3,5,6)$. Bu makalede kliniğimize parmak uçlarında ve dudaklarda morarma şikâyeti ile başvuran ve PAVM tanısı alan iki çocuk olgu sunulmuştur. 


\section{Olgu Sunumu}

\section{Olgu 1}

Íki yașındaki kIz olgu, doğumundan itibaren mevcut olan "parmaklarda morarma" yakınması ile bașvurduğu sağlık kuruluşu tarafından siyanotik konjenital kalp hastalığı ön tanısı ile hastanemize yönlendirilmiști. Özgecmişinde; miadında, normal spontan yolla 3150 gr olarak doğduğu ve parmaklarda morarma dışında herhangi bir sağlık problemi olmadığı kaydedildi. Soy gecmişinde; ailede akrabalık, siyanotik kalp hastalığı ya da kronik akciğer hastalığı öyküsü mevcut değildi. Hastanın yapılan kardiyak değerlendirilmesinde; telekardiyografi, EKG, ekokardiyografi, arteriyal kan gazı incelemesi sonucunda konjenital kalp hastalığı düşünülmedi. Methemoglobin düzeyi normaldi. Akciğer perfüzyon sintigrafisinde her iki akciğerin homojen olarak perfüze olması ve dinamik çalıșmada patolojik bulgu izlenmemiş olması nedeniyle çomak parmak etiyolojisindeki diğer nedenlerin araștııılması için olgu Çocuk Göğüs Hastalıkları polikliniği tarafından değerlendirilen olgunun geliş fizik muayenesinde; vücut ağırlığı: 11,200 gr (\%25-50p), boy: $90 \mathrm{~cm}(\% 75 p)$, vücut ISISI: $36,5^{\circ} \mathrm{C}$, solunum sayısI: 30/dk, nabız: 118/dk, kan basıncl: 80/45 mmhg, Sa02: \%75 olarak saptandı. Solunum sesleri bilateral eșit alınmaktaydı ve ek ses mevcut değildi. Kardiyak oskültasyon normal olup ek ses, üfürüm yoktu. Nabızlar 4 ekstremitede eşit olarak alınmaktaydı. El parmaklarda çomak parmak deformitesi ve tırnaklarda siyanoz izleniyordu. Diğer sistem muayenelerinde belirgin özellik yoktu.

Laboratuvar incelemelerinde; hemoglobin: 13,9 gr/dl, Hct: \%39, beyaz küre: $10.800 / \mathrm{mm}^{3}$ (\%48 parçalı, $\% 52$ lenfosit), trombosit: $398.000 / \mathrm{mm}^{3}$, eritrosit sedimentasyon hızl: $12 \mathrm{~mm} / \mathrm{saat}$, C-reaktif protein: <1 $\mathrm{mg} / \mathrm{l}$ olup biyokimya incelemeleri normaldi. Radyolojik incelemesinde; akciğer grafisinde sağ akciğerde parakardiyak dansite artımı (Resim 1) izlenmesi üzerine olguya toraks BT görüntülemesi yapıldı. Toraks BT' de; sağ alt lobda dilate, tortios görünümde, pulmoner damarlanma alanına ait olması muhtemel, lobüle konturlu yumușak doku alanı izlendi (Resim 2). Toraks BT görüntüleri sağ alt lobda vasküler malformasyonla uyumlu olarak değerlendirilen olguya toraks MR görüntülemesi yapıldı. Toraks MR da sağ pulmoner arter normalden geniş olup devamında sağ pulmoner venlere bağlantılı arteriovenöz malformasyon ile uyumlu vasküler olușum izlendi (Resim 3). Bu bulgularla olgu PAVM tanısı aldı.

\section{Olgu 2}

Onüç yaşındaki kız olgu; dudaklarda, gözaltlarında ve tırnak uçlarında morarma yakınması ile hastanemiz

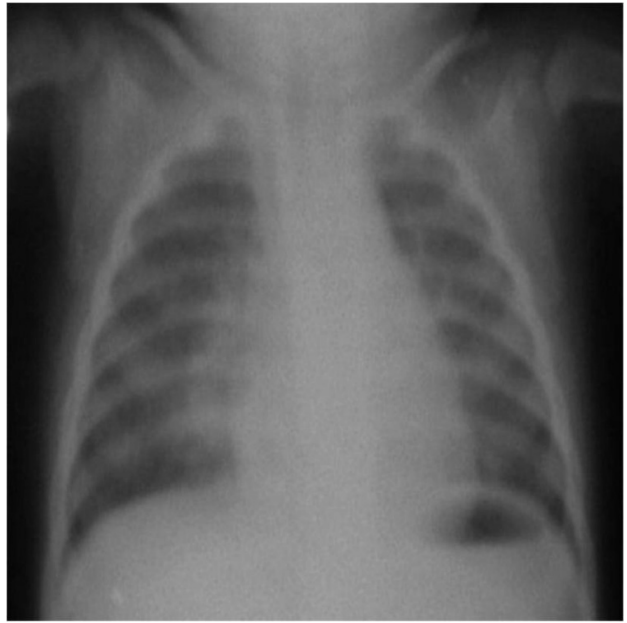

Resim 1. Illk olgunun akciğer grafisinde sağ akciğerde parakardiyak dansite artımı

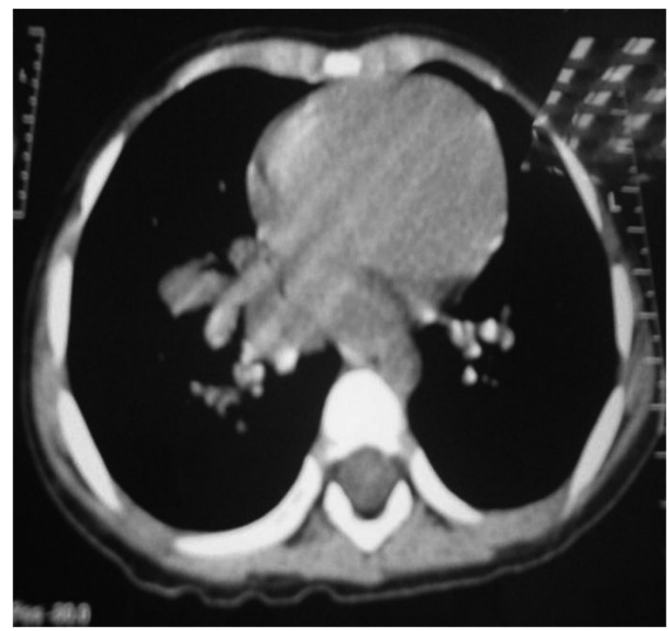

Resim 2. Illk olgunun toraks BT görüntülemesinde; sağ alt lobda dilate, tortios pulmoner damarlanma alanına ait olması muhtemel, Iobüle konturlu yumuşak doku alanı

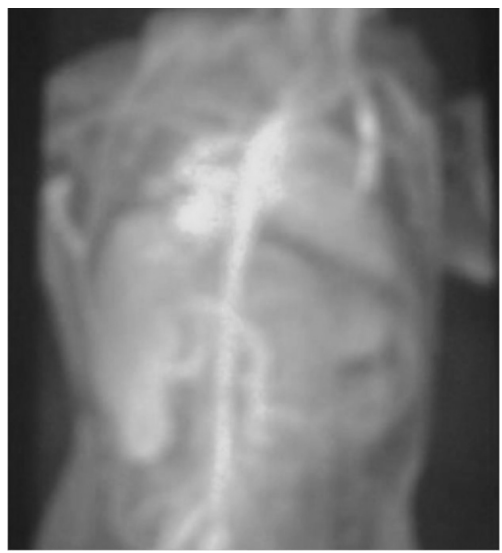

Resim 3. Tílk olgunun toraks MR görüntülemesinde; sağ pulmoner arter normalden geniş olup devamında sağ pulmoner venlere bağlantılı arteriovenöz malformasyon ile uyumlu vaskuler oluşum 
başvurmuştu. Özgecmişinde; miadında, normal spontan yolla 2750 gr olarak doğduğu, dudak ve tırnak uçlarında morarma dışında herhangi bir sağlık problemi olmadığı kaydedildi. Soygeçmişinde ailede akrabalık öyküsü, benzer siyanotik kalp hastalı̆̆ ya da kronik akciğer hastalığı öyküsü mevcut değildi. Kardiyak fizik muayene ve ekokardiyografi bulguları normal olarak değerlendirilen olgu, siyanoz ve çomak parmak etyolojisine yönelik değerlendirme için Çocuk Göğüs Hastalıkları polikliniğine yönlendirilmişti.

Olgunun geliş fizik muayenesinde; vücut ağırlığı: 41 kg (\%10p), boy: $163 \mathrm{~cm}$ (\%75p), vücut ISISI: $36,5^{\circ} \mathrm{C}$, solunum sayısI: $26 / d k$, nabız: 90/dk, kan basıncl: 110/80 $\mathrm{mmHg}, \mathrm{SpO}_{2}$ : \%76 olarak saptandı. Solunum sistemi ve kardiyovaskuler sistem muayenesi olağandı. El parmaklarında çomak parmak deformitesi ve dudaklarda siyanoz dışında patolojik muayene bulgu mevcut değildi. Laboratuvar incelemelerinde hemoglobin: $17 \mathrm{gr} / \mathrm{dl}$, Hct: $\% 50$, beyaz küre: $10.130 / \mathrm{mm}^{3}$ (\%52 parçall, $\% 48$ lenfosit), trombosit: $457.000 / \mathrm{mm}^{3}$, eritrosit sedimentasyon hızl: $2 \mathrm{~mm} / \mathrm{saat}$, biyokimya incelemeleri normaldi. Radyolojik incelemesinde; akciğer grafisinde sağ akciğerde parakardiyak dansite artımı (Resim 4) izlenmesi üzerine olguya toraks BT görüntülemesi yapıldı. Toraks BT'de sağ orta lob medial segmentte kalın bir pulmoner arter dalı ile beslenen, çapı 38 mm'yi bulan damar yumağı ile karekterize arteriovenöz malformasyon izlendi. Bu malformasyon superior pulmoner vene drene olduğu gözlendi (Resim 5). Bu bulgularla olgu PAVM tanısı aldı.

Her iki olgumuz PAVM ile ilișkili olarak oda havasında hipoksemi bulguları olması ve semptomatik olmaları nedeniyle endovasküler embolizasyon için ilgili merkeze sevk edildi.

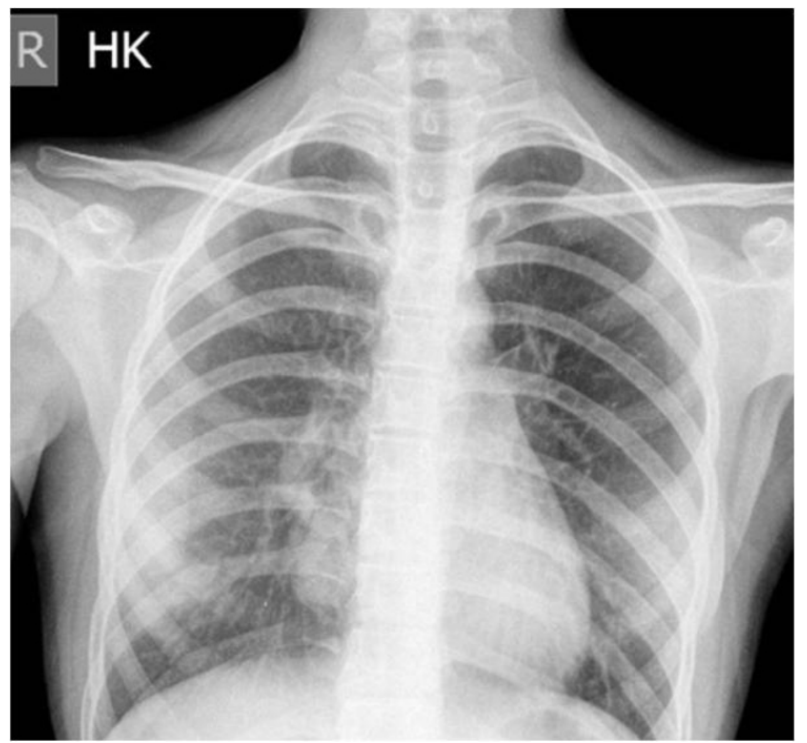

Resim 4. Íkinci olgunun akciğer grafisinde sağ parakardiyak dansite artımı

\section{Tartışma}

PAVM'ler anormal kapiller gelişimden kaynaklanan, çoğunlukla konjenital lezyonlardır (1). Etyolojisi tam olarak bilinmemekle birlikte, bazı genetik faktörlerin hastalığın oluşumunda rol oynadığı düşünülmektedir. Olguların \%10'unu çocuklar oluşturmakta ve insidans 5. ve 6. dekatta artmaktadır $(1,7)$. Dines ve arkadaşları, 1974 yılında AVM'leri ROWH diğer adı ile HHT ile birlikte olanlar ve idiopatik AVM'ler olarak iki gruba ayırmışlardır (8). Pulmoner AVM'li olgular genellikle konjenital olup $\% 70$ ROWH ile birlikte görülmektedir. Edinsel olarak da; göğüs travması, metastatik tiroid karsinomu, karaciğer sirozu, mitral stenoz, Fanconi sendromu ve enfeksiyonlara (aktinomikoz, şistozomiyazis, tüberküloz, sifiliz) sekonder olarak gelişmektedir $(1,7)$.

Konjenital PAVM'ler kadınlarda daha sık görülür ve inkomplet geçişli dominant bir gen ile iletilir. Sıklıkla PAVM'ler soliter, süperfisyel yerleşimlidir ve alt lobları tutar. Olguların \%33-50 sinde çoklu olabilir ve sıklıkla HHT ile birliktedir (9). Ayrıca HHT ile birlikte olan PAVM'ler hızlı progresyon gösterir ve komplikasyon oranı oldukça yüksektir $(3,9)$. Bizim her iki olgumuzda da AVM tektir ve ilk olgumuzda alt lob ikinci olgumuzda ise orta lobda yerleşim göstermektedir.

PAVM'lerde semptomlar sayı ve lezyonun boyutuna göre değişebilmektedir. Iki cm'den küçük ve tek olanlar genellikle asemptomatik seyretmekte iken, iki cm'den büyük olanlarda ise öksürük, nefes darlığı, hemoptizi, siyanoz, epistaksis gibi semptomlar ortaya çıkabilmektedir. Klasik triad (siyanoz, polisitemi ve çomak parmak) çocuklarda nadirdir. Kapiller geçiş sisteminin ortadan kalkması sonucunda gelişen şanta bağlı olarak paradoksik

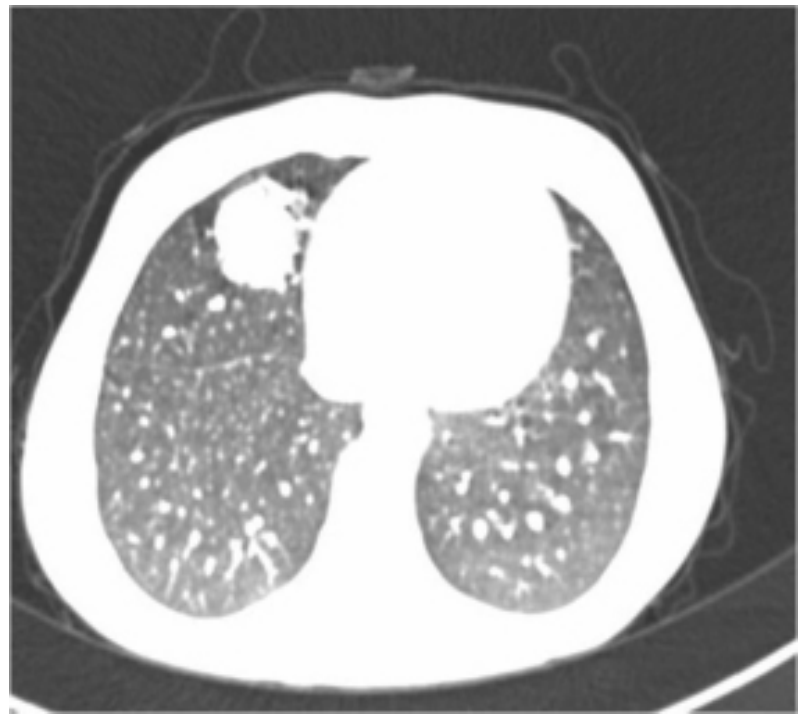

Resim 5. kinci olgunun toraks BT görüntülemesinde; sağ orta lob medial segmentte yüksek debili pulmoner AVM ile uyumlu görünüm 
emboliler ve hemipleji, beyin apsesi gibi serebrovaskuler komplikasyonlar ortaya çıkabilmektedir $(3,6,10)$. Her iki olgumuzda da yüksek debili PAVM'ye bağlı şant nedeniyle klasik triad (siyanoz, polisitemi ve çomak parmak) tespit edilmiștir.

PAVM'lerin klasik radyolojik görünümü, yuvarlak ya da oval, uniform yoğunlukta dansite artıș șeklindedir. Sıklıkla lobule fakat keskin sınırlı, genellikle alt loblarda ve çapı $1-5 \mathrm{~cm}$ arasındadır (10). Akciğer grafileri kesin tanı için yetersizdir. Kontrastlı ekokardiyografi, kontrastlı toraks ve dinamik BT, manyetik rezonans anjiyo (MRA) ve tanıda "altın standart" kabul edilen pulmoner anjiyografi diğer ileri tetkiklerdendir. Pulmoner anjiografi standart yöntem olmakla birlikte invazivdir, belli oranda mortalite ve morbiditeye yol açar. Bu yüzden pulmoner anjiyografi tüm noninvaziv incelemelerden sonra tanı konulamamış ise veya tedavide "coil" embolizasyon denenecek ise tercih edilmelidir (11).

PAVM'li hastalarda ikinci basamak görüntüleme yöntemi genellikle toraks BT olmaktadır. Toraks BT'de AVM'ler kan damarları ile bağlantılı serpenjinöz kitle ya da iyi sınırlı nodüler kitle şeklinde kendini gösterir. Toraks BT, lezyonun lob ya da segmental yerleşimini, anatomisini ve kontrastlanma zamanını gösterir. Remy J. ve ark.'nın yaptığı bir çalışmada toraks BT ile \%98,2 oranında PAVM teşhisi konulmuştur (12). Dinamik akciğer tomografisi de AVM tanısı için değerli bir yöntemdir. Dinamik BT incelemesinde AVM'ler tipik olarak sağ ventrikülden ya da pulmoner arterden sonra sol atrium ve ventrikülden önce kontrast tutarlar (12). Olgularımıza akciğer grafilerindeki kuşkulu lezyonun toraks BT ile değerlendirilmesi sonucu tanı konulmuştur.

Son zamanlarda torasik vasküler yapıların ve lezyonların incelenmesinde üç boyutlu manyetik rezonans anjiyografi (MRA), tercih edilen yöntem olmuştur. Üç boyutlu MRA inceleme ile vasküler anatomi ve AVM'yi besleyen arter/ ven drenajı doğru bir ssekilde görüntülenebilmektedir. Üç boyutlu MRA'nın, özellikle $5 \mathrm{~mm}$ 'nin üzerinde besleyen arter çapı olan AVM'de, \%100 başarılı olduğunu gösteren çalışmalar mevcuttur $(12,13)$. Illk olgumuzda da PAVM tanısı MRA ile verifiye edilmiştir.

PAVM'li olgularda tedavi endikasyonlarl; hipoksemi semptomu olan olgular, ROWH ve çoklu AVM olarak sıralanır. Hasta asemptomatik olsa bile besleyici arter çapı 3 mm'den geniş ise gelişebilecek komplikasyonlar nedeniyle mutlaka tedavi planlanmalıdır $(2,14)$. Transkatater embolizasyondan önce AVM'ler lobektomi, wedge rezeksiyon, arter ligasyonu gibi yöntemlerle tedavi edilmekte iken günümüzde transkateter embolizasyon hipoksemiye yol açan, besleyici arter çapı 3 mm'den büyük PAVM tedavisinde başarıyla uygulanmaktadır $(3,14)$. Cerrahi yöntem ise lokalize, soliter, büyük, embolizasyona rağmen düzelmeyen veya rüptüre olarak hemotoraksa neden olmuş PAVM'lerde küratif ve güvenli bir yöntemdir $(2,15)$. Her iki olgumuz da şanta bağlı olarak hipoksemi bulguları olması ve AVM çapının 3 mm'den fazla olması nedeni ile gelişebilecek komplikasyonların önlenmesi amacıyla transkateter embolizasyon için uygun merkeze sevk edilmiștir.

Sonuç olarak çocukluk çağında genellikle konjenital kalp hastalığı ile ilişkilendirilen çomak parmak ve siyanoz birlikteliğinde pulmoner arteriyovenöz malformasyonların akla gelmesi ve tanı için mutlaka ileri radyolojik tetkiklerin istenmesinin gerekliliği vurgulanmak istenmiştir.

\section{Kaynaklar}

1. Shields TW. Congenital vascular lesions of the lungs. General thoracic surgery. 5th ed. Lippincot Williams \& Wilkins 2000;975-87.

2. Liptay MJ, Ujiki MB, Locicero J. Congenital vascular lesions of the lungs. In: Shields WT (ed). General Thoracic Surgery. 6th ed. Philadephia: 2004:1144-52.

3. Coley SC, Jackson JE. Review pulmonary arteriovenous malformations. Clinical Radiology 1998;53:396-404.

4. Guttmacher AE, Marchuk DA, White RI Jr. Hereditary hemorrhagic telengiectasia. N Engl J Med 1995;339:918-24.

5. Borrero CG, Zajko AB. Pulmonary arteriovenous malformations: clinical features, diagnosis and treatment. J Radiol Nurs 2006;25:33-7.

6. Cottin V, Plauchu H, Bayle JY, Barthelet M, Revel D, Cordier JF. Pulmonary arteriovenous malformations in patients with hereditary hemorrhagic telangiectasia. Am J Respir Crit Care Med 2004;169:994-1000.

7. Gossage JR, Kanj G. Pulmonary arteriovenous malformations. A state of the art review. Am J Respir Crit Care Med 1998;158:643-61.

8. Dines DE, Seward JB, Bernatz PE. Pulmonary arteriovenous fistulas. Mayo Clin Proc 1983;58:176-81.

9. Hoffman WS, Weinberg PM, Ring E, Edmunds LH Jr. Massive hemoptysis secondary to pulmonary arteriovenous fistula. Treatment by a catheterization procedure. Chest 1980;77:697700.

10. Ference BA, Shannon TM, White RI Jr, Zawin M, Burdge CM. Life-threatening pulmonary hemorrhage with pulmonary arteriovenous malformations and hereditary hemorrhagic telangiectasia. Chest 1994;106:1387-90.

11. White RI Jr. Pulmonary arteriovenous malformations: how do I embolize? Tech Vasc Interv Radiol 2007;10:283-90.

12. Remy J, Remy-Jardin M, Wattinne L, Deffontaines C. Pulmonary arteriovenous malformations: evaluation with CT of the chest before and after treatment. Radiology 1992;182:809-16.

13. M. Puvanesary. $3 \mathrm{D}$ gadolinium-enhanced $M R$ angiography of pulmonary AVM. Australasian Radiology 2002;46:189-93.

14. Vrachliotis TG, Bis KG, Kirsch MJ, Shetty AN. Contrastenhanced MRA in pre-embolization assessment of a pulmonary arteriovenous malformation. J Magn Reson Imaging 1997;7:434-6.

15. Mann MJ, Kramer MJ, Hall TS, Anastassiou P, Katz J, Golden J, et al. Isolated pulmonary arteriovenous malformations requiring anatomic resection. J Thorac Cardiovasc Surg 2004;127:574-6. 